\title{
Acrokeratoelastoidosis and focal acral hyperkeratosis: Report of two cases
}

\author{
Hatice Duman', Ilteris Oguz Topal', Caglar Cakır² \\ ${ }^{1}$ Department of Dermatology, Okmeydani Training and Research Hospital, Istanbul, Turkey, ${ }^{2}$ Department of Pathology, \\ Okmeydani Training and Research Hospital, Istanbul, Turkey
}

Corresponding author: Dr. Hatice Duman, E-mail: hatice-ergun15@hotmail.com

\begin{abstract}
ABSTACT
Acrokeratoelastoidosis (AKE) and focal acral hyperkeratosis (FAH) are rare type of palmoplantar keratodermas. AKE and FAH show similar clinical features and identical histologic dermal alterations. However, FAH lacks elastorrhexis, a major distinguishing feature between the two. We herein report a sporodic AKE in a 62 year-old female and a sporodic FAH in a 4l-year-old female.
\end{abstract}

Key words: Acrokeratoelastoidosis; Focal acral hyperkeratosis; Keratoderma

\section{INTRODUCTION}

Marginal papular acrokeratodermas (MPA) are a group of disorders that have keratotic papules along the borders of the hands and feet as a common clinical feature [1]. Acrokeratoelastoidosis (AKE) and focal acral hyperkeratosis (FAH) are rare clinical variants of MPA $[2,3]$. We herein report a sporodic AKE in a 62 year-old female and a sporodic FAH in a 41 -year-old female.

\section{CASE REPORT}

\section{Case 1}

A 62-year-old woman presented with multiple, asymptomatic, firm, yellowish to flesh-coloured papules distributed along the border of the thenar regions of the palms, thumbs, and dorsal surfaces of the hands (Fig. 1). The lesions had begun in childhood and the number of lesions had gradually increased in years. No family member had similar lesions. Histopathological examination of the papules showed hyperkeratosis, prominent granular zone, acanthosis, focal clavus-like depression of the epidermis. Van Gieson elastic stain revealed coarse, fragmentation and a reduced number of elastic fibers in the reticular dermis (Figs. 2a and 2b). Based upon these findings, a diagnosis of AKE was established.

\section{Case 2}

A 4l-year-old woman presented with multiple, asymptomatic, shiny, firm, yellowish to flesh-coloured papules clustered on the ventral and dorsal surfaces of the hands (Fig. 3). The lesions had begun 16 years before and the number of lesions had gradually increased within the last two years. The patient had no family history of a similar cutaneous disorder. Histopathological examination of lesional skin showed hyperkeratosis, hypergranulosis, and focal clavus-like depression of the epidermis. No specific changes were detected in the dermis. Orcein staining showed no evidence of elastorrhexis (Figs. 4a and b). Based upon these findings, a diagnosis of FAH was established.

\section{DISCUSSION}

Acrokeratoelastoidosis was first described by Costa in 1953 [2]. In 1983 Dowd and et al. described fifteen patients clinically identical to acrokeratoelastoidosis, but without elastorrhexis. This condition which differs

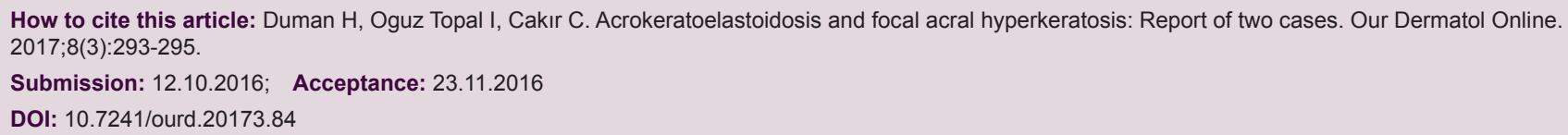




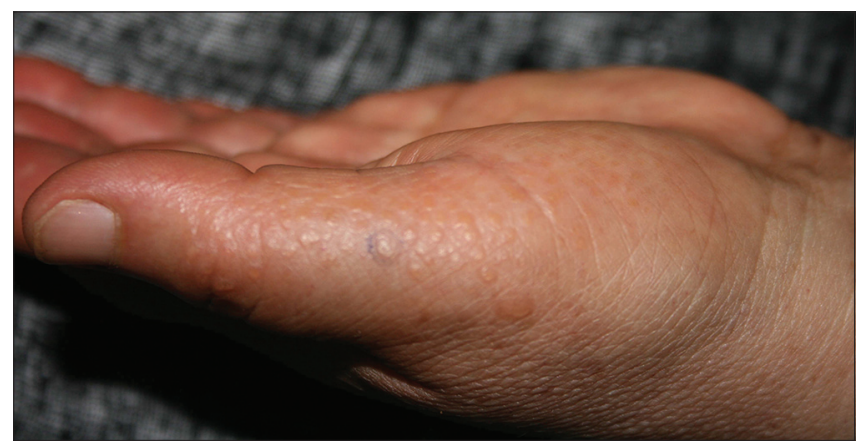

Figure 1: Multiple, yellowish to flesh colored, papules on the lateral margin of the hand.

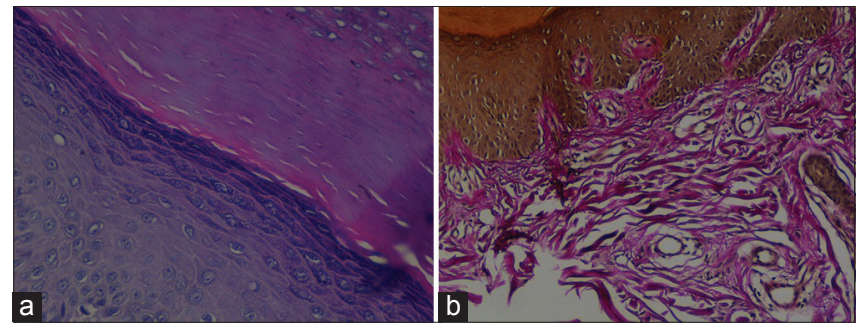

Figure 2. a: Hematoxylin and eosin stain showing orthohyperkeratosis and hypergranulosis (original magnification $\times 100$ ). b: Verhoeff's-Van Gieson staining showing fragmented thinned elastic fibers (original magnification $\times 100$ ).

histologically from AKE was named FAH [4]. They suggested that FAK is a focal disorder of keratinization of unknown etiology rather than a disease of the elastic fibers as in acrokeratoelastoidosis [2]. However, some authors consider FAH to be a distinct entity or others think that FAH is a variant of AKE [1,5-7]. Both disorders are either sporadic or familial, with an apparent autosomal dominant inheritance $[2,3,8]$. Our both cases were sporadic.

Clinically, both conditions are characterized by asymptomatic, multiple, small, shiny, smooth, firm, and yellowish papules, sometimes umbilicated, located symmetrically on both thenar and hypothenar regions, the volar aspect of the wrist, dorsa and sides of the digits, and radial and ulnar margins of the hands. The dorsa of the feet and toes, and soles may also be affected [5]. Clinically, these two similar entities were distinguished by histopathological features. Histologically AKE and FAH both show orthohyperkeratosis overlying a crateriform depression in the epidermis. However, FAH lacks elastorrhexis, a major distinguishing feature between the two [3]. Our both cases showed similar clinic presentation. Histopathologically, our first case showed elastorrhexis but our second case showed no elastorrhexis. According to these findings, our first case was diagnosed as AKE and our second case was diagnosed as FAH.

(c) Our Dermatol Online 3.2017

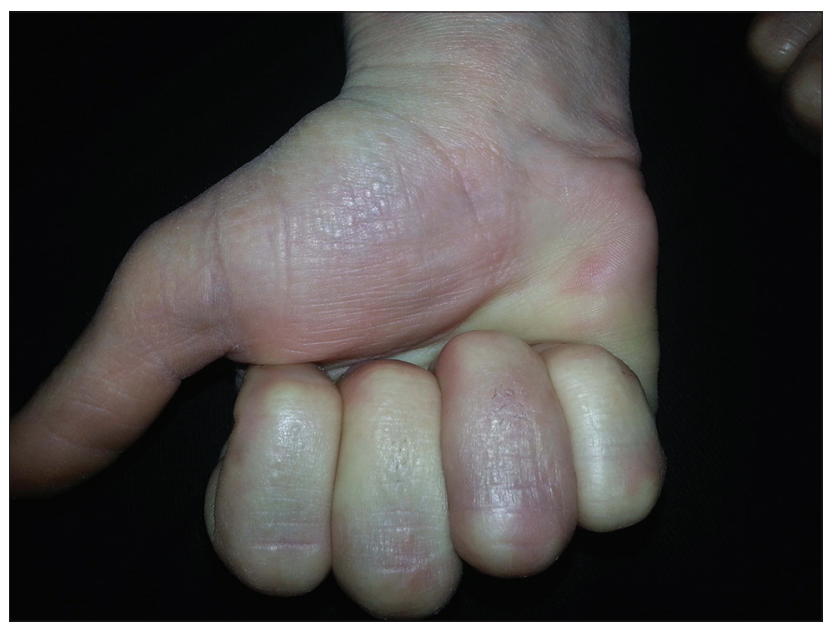

Figure 3: Multiple, brilliant, yellowish to flesh-coloured papules on the dorsal and ventral hand surfaces.

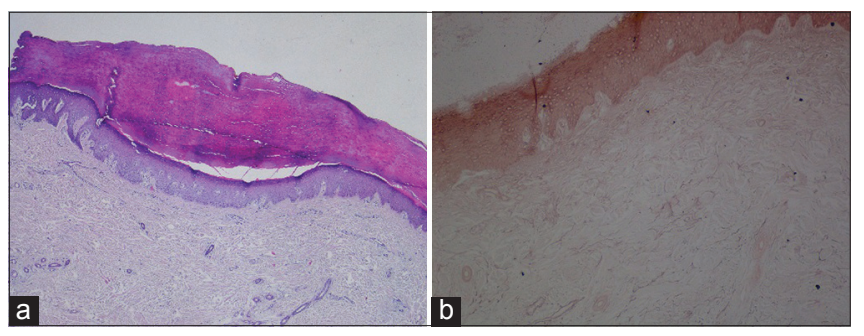

Figure 4. a: Hematoxylin and eosin stain showing hyperkeratosis with acanthosis (original magnification $\times 40$ ). b: Orcein staining demonstrating the intact elastic fiber frame in the dermis (original magnification $\times 100$ ).

AKE and FAH must be differentiated from verruca plana, acrokeratosis verruciformis of Hopf, degenerative collagenous plaques of the hands, digital papular calcinosis, mosaic acral keratosis, and hereditary papulotranslucent acrokeratoderma punctate porokeratosis and punctate palmoplantar keratoderma $[3,6,8]$.

AKE and FAH have been rarely reported in the English literature with unkown etyology. Clinical and histopathological findings are the most important tools to define diagnosis and distinguish the other keratinization disorders. Additional case reports and further genetic studies are requaried to more understanding of the diseases.

\section{Consent}

The examination of the patient was conducted according to the Declaration of Helsinki principles.

\section{REFERENCES}

1. Rongioletti F, Betti R, Crosti C, Rebora A. Marginal papular acrokeratodermas: A unified nosography for focal acral hyperkeratosis, acrokeratoelastoidosis and related disorders. 


\section{www.odermatol.com}

Dermatology. 1994;188:28-31.

2. Shbaklo Z, Jamaleddine NF, Kibbi AG, Salman SM, Zaynoun ST. Acrokeratoelastoidosis. Int J Dermatol. 1990;29:333-6.

3. Lee EA, Kim HS, Kim HO, Park YM. A case of focal acral hyperkeratosis. Ann Dermatol. 2009;21:426-8.

4. Dowd PM, Harman RR, Black MM. Focal acral hyperkeratosis. Br J Dermatol. 1983; 109:97-103.

5. Abulafia J, Vignale RA. Degenerative collagenous plaques of the hands and acrokeratoelastoidosis: Pathogenesis and relationship with knuckle pads. Int J Dermatol. 2000;39:424-32.

6. Lee SE, Kim SC. Focal acral hyperkeratosis. Clin Exp Dermatol. 2007;32:608-10.
7. Fiallo P, Pesce C, Brusasco A, Nunzi E. Acrokeratoelastoidosis of Costa: A primary disease of the elastic tissue? J Cutan Pathol. 1998;25:580-2.

8. Meziane M, Senouci K, Ouidane Y, Chraïbi R, Marcil T, Mansouri F, et al. Acrokeratoelastoidosis. Dermatol Online J. 2008;14:11.

Copyright by Hatice Duman, et al. This is an open access article distributed under the terms of the Creative Commons Attribution License, which permits unrestricted use, distribution, and reproduction in any medium, provided the original author and source are credited.

Source of Support: Nil, Conflict of Interest: None declared. 